\title{
Ultrasonographic characteristics of accessory sex glands and spectral Doppler indices of the internal iliac arteries in peri- and post-pubertal Dorper rams raised in a subtropical climate
}

\author{
E.S.C. Camela ${ }^{a}$, R.P. Nociti ${ }^{a}$, V.J.C. Santos ${ }^{a}$, B.I. Macente ${ }^{a}$, G.S. Maciel ${ }^{a}$, \\ M.A.R. Feliciano ${ }^{\text {a }}$, W.R.R. Vicente $^{\mathrm{a}}$, I. Gill ${ }^{\mathrm{b}}$, P.M. Bartlewski ${ }^{\mathrm{b}}$, M.E.F. Oliveira ${ }^{\mathrm{a}, *}$

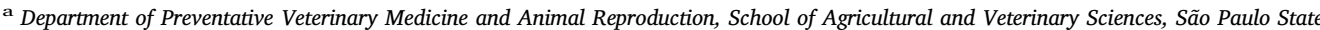 \\ University, Jaboticabal, São Paulo, 14.884-900, Brazil \\ b Department of Biomedical Sciences, Ontario Veterinary College, University of Guelph, Guelph, ON, N1G 2W1, Canada
}

\section{A R T I C L E I N F O}

\section{Keywords:}

Ram

Vesicular glands

Prostate

Bulbourethral glands

Ultrasonography

Internal iliac artery

\begin{abstract}
A B S T R A C T
The aim of the present study was to determine and compare ultrasonographic characteristics of accessory sex glands and spectral Doppler indices of the internal iliac arteries in peri- and postpubertal rams raised in a subtropical climate. Forty-five Dorper rams were examined (24 rams aged 8-11 months and 21 rams aged 12-24 months). Digital images of all accessory sex glands were subjected to morphometric and echotextural analyses, the latter using commercially available image analytical software Image ProPlus . Physical and morphological characteristics of semen and serum concentrations of testosterone were also determined. The dimensions of the prostate gland $(12.9 \pm 1.2$ compared with $14.2 \pm 2.7 \mathrm{~mm}$; mean \pm standard deviation) and bulbourethral glands $(13.7 \pm 1.3$ compared with $14.7 \pm 1.8 \mathrm{~mm})$ were greater $(P=0.04)$ in sexually mature compared with peri-pubertal rams. Pixel intensity of vesicular $(181.5 \pm 20.8$ compared with $164.8 \pm 26.8, P=0.02)$ and bulbourethral gland parenchyma $(166.9 \pm 16.9$ compared with $141.8 \pm 29.1, P=0.001$ ) was greater in peri-pubertal compared with sexually mature rams. Semen could be collected by ejaculation into the artificial vagina from $38 \%(8 / 21)$ of post-pubertal rams and $21 \%(5 / 24)$ of peri-pubertal animals $(P=0.03)$. Semen volume was positively correlated with peak systolic velocity (PSV) and end-diastolic velocity (EDV) in the internal iliac arteries $(r=0.79, P=0.001$ and $r=0.67, P=0.01$, respectively), while spermatic vigor and progressive motility were inversely related to circulating concentrations of testosterone ( $r=-0.69, P=0.009$ and $r=-0.61, P=0.03$, respectively). In summary, the attainment of sexual maturity in the rams of the present study was associated with an enlargement of the prostate and bulbourethral glands, and with the shift in echotextural attributes of vesicular and bulbourethral glands. Circulating testosterone concentrations and Doppler blood flow indices of the ram's internal iliac arteries are significant predictors of sperm progressive motility, vigor and the amount of ejaculate.
\end{abstract}

\section{Introduction}

Male accessory sex glands produce secretions that constitute an energy source for spermatozoa, facilitate movement of the sperm

\footnotetext{
* Corresponding author at: Department of Preventative Veterinary Medicine and Animal Reproduction, College of Agricultural and Veterinary Sciences, São Paulo State University, Jaboticabal, São Paulo, Via de acesso Professor Paulo Donato Castellane, s/n, 14.884-900, Brazil.

E-mail address: m.emiliafraoli@fcav.unesp.br (M.E.F. Oliveira)
} 
along the ejaculatory duct, and provide a natural protective buffer against the acidic environment of the vagina (Mann, 1946). Even though the accessory sex glands contribute significantly to mammalian fertlity (Pang et al., 1979), they receive very little attention during routine breeding soundness evaluation (BSE) of livestock species (Gouletsou and Fthenakis, 2010). The accessory sex organs (deferent duct ampullae, vesicular glands, prostate, and bulbourethral glands) located in the pelvic cavity are frequently neglected during BSE in small ruminants due to difficulty in performing rectal palpation; their proper function is typically evaluated indirectly through the assessment of seminal fluid quantity and chemical composition. The application of transrectal ultrasonography created a new possibility for monitoring macro- and microscopic changes in the accessory sex glands (Chandolia et al., 1997; Clark and Althouse, 2002), but sonographic studies of these organs in rams are still scarce.

The B-mode, grey-scale ultrasonography enables the visualization of internal reproductive organs (Chandolia et al., 1997) and evaluation of their size, shape, and echotexture (Muramoto et al., 2011). An ultrasonogram is a matrix of square brighnteness elements called pixels (Chandolia et al., 1997), whose intensity and uniformity (i.e., echotextural attributes) determined by computerized image analyses are indicative of microstructure and chemical composition of the organs and tissues examined (Omer et al., 2012). The pattern of changes if numerical pixel values of testicles, prostate and vesicular glands between 4 and 26 weeks of age was documented in spring-born Suffolk ram lambs (Chandolia et al., 1997) but there has been no assessment of peripubertal changes in the echotexture of bulbourethral glands, and no study of the association among ultrasonographic characteristics of the reproductive organs, circulating testosterone concentrations and semen parameters in ram lambs and rams raised in a subtropical area.

Doppler ultrasonography is a relatively new diagnostic tool in veterinary practice and reproductive research. Used in conjunction with conventional (grey-scale) ultrasonography, Doppler imaging can provide the information on vascular integrity and blood flow in the male reproductive system (Carvalho et al., 2008). Spectral Doppler (velocimetric) parameters are important indicators of blood perfusion and physiological status of internal organs. Doppler ultrasound is used in andrology to assess the blood flow in the testicular artery, aiding in the diagnosis of testicular disorders and abnormal spermatogenesis (Pinggera et al., 2008). It was proposed that blood flow parameters mesured in the testicular artery, namely blood flow resistance and pulsatilty index, are significant predictors of semen quality (Gumbsch et al., 2002; Carrillo et al., 2012; Zelli et al., 2013). There is a paucity of studies on blood flow dynamics in the arteries supplying the accessory sex glands of rams and their associations with semen quality.

Therefore, the primary goal of the present study was to determine and compare ultrasonographic attributes of the accessory sex organs and spectral Doppler indices of the internal illiac arteries in peri- and post-pubertal rams to see if they can be used for the assessement of sexual maturation and reproductive potential of rams. In addition, various morphometric and echotextural characteristics of accessory sex glands, hemodynamic indices of the internal iliac artries, and cirulating testosterone concentrations were examined for correlations with semen characteristics in peri- and post-pubertal rams under subtropical conditions.

\section{Material and methods}

All experimental procedures were compliant with the guidelines on the Ethics and Animal Welfare, and had been formally approved by the School of Agricultural and Veterinary Sciences (FCAV) Animal Care Committee, São Paulo State University, Jaboticabal, SP, Brazil (protocol no. 06385/14).

The study was conducted in a commercial farm $\left(23^{\circ} 31^{\prime} 45^{\prime \prime} \mathrm{S}\right.$ and $\left.47^{\circ} 08^{\prime} 07^{\prime \prime} \mathrm{W}\right)$ and utilized forty-five clinically healthy Dorper rams that were allocated to two age groups: 1$)$ peri-pubertal rams $(n=24$; mean age of $9.0 \pm 1.0$ months and weighing $61.2 \pm 9.6 \mathrm{~kg}$; mean \pm standard deviation); and 2) post-pubertal or sexually mature rams ( $n=21$; mean age of $16.6 \pm 4.5$ months and weighing $70.4 \pm 15.2 \mathrm{~kg}$ ). The average age at puberty in rams maintained in subtropical regions (defined as the age at which rams are first capable of producing fertile sperm) is approximately 8 months (Alves et al., 2006); however, the full reproductive and breeding capacity is only achieved at approximately 12 months of age (Snowder et al., 2002). In addition to general clinical examinations, the visual inspection of the scrotum and testicular palpation for the evaluation of consistency, symmetry, mobility and sensitivity of testicles were performed. All animals were kept in outdoor group pans and had unrestricted access to water, mineral salt bars and corn silage; concentrated feed (based on soybean meal and corn husked with $19 \%$ crude protein) was supplied in the amount of $500 \mathrm{~g} / \mathrm{animal} /$ day.

All ultrasonographic examinations were carried out by a single experienced operator using a portable scanner (MyLab 30 Gold Vet; Esaote, Genova, Italy) connectecd to a 7.5-MHz transducer fitted with a slightly curved plastic extension tube (length: $30 \mathrm{~cm}$ ). The animals were restrained manually and examined in the standing position. After removal of feces present in the rectum, the head of the transducer was covered with lubricating gel and placed in the rectum dorsally to the urinary bladder. The transducer was then slowly rotated in order to visualize and capture images of the accessory sex glands; the images of all organs of interest were aquired during a single transrectal examination spanning approximately $5 \mathrm{~min}$.

Measurements of the accssory sex glands were taken with built-in electronic calipers, using the images containing the largest cross-sectional area of the specific regions of each organ (Fig. 1A-C). Two dimensions (dorsoventral and craniocaudal) of vesicular and bulbourethral glands were taken, and three portions (cranial, middle and caudal; dorsoventral dimensions) of the prostate gland were measured. The main gain was set to $65 \%$ of a maximum value and a single focal point was positioned in the region of interest; all settings including the near and far gain and contrast were kept constant throughout the study period.

Commercially available image analytical software (Image ProPlus ${ }^{\circledR}$; Media Cybernetics Inc., San Diego, CA, USA) was used for quantitative image analysis of all ultrasonograms. Artifact-free images of accessory sex glands containing the largest cross-sectional area of the gland were selected for computer-assisted assessments. Mean numerical pixel values (NPVs) and pixel heterogeneity (standard deviation of NPVs) were computed within one (prostate gland) or six to seven (vesicular and bulbourethral glands) circular regions of interest (spot meters) placed within the parenchyma of the organs (Ahmadi et al., 2013). 

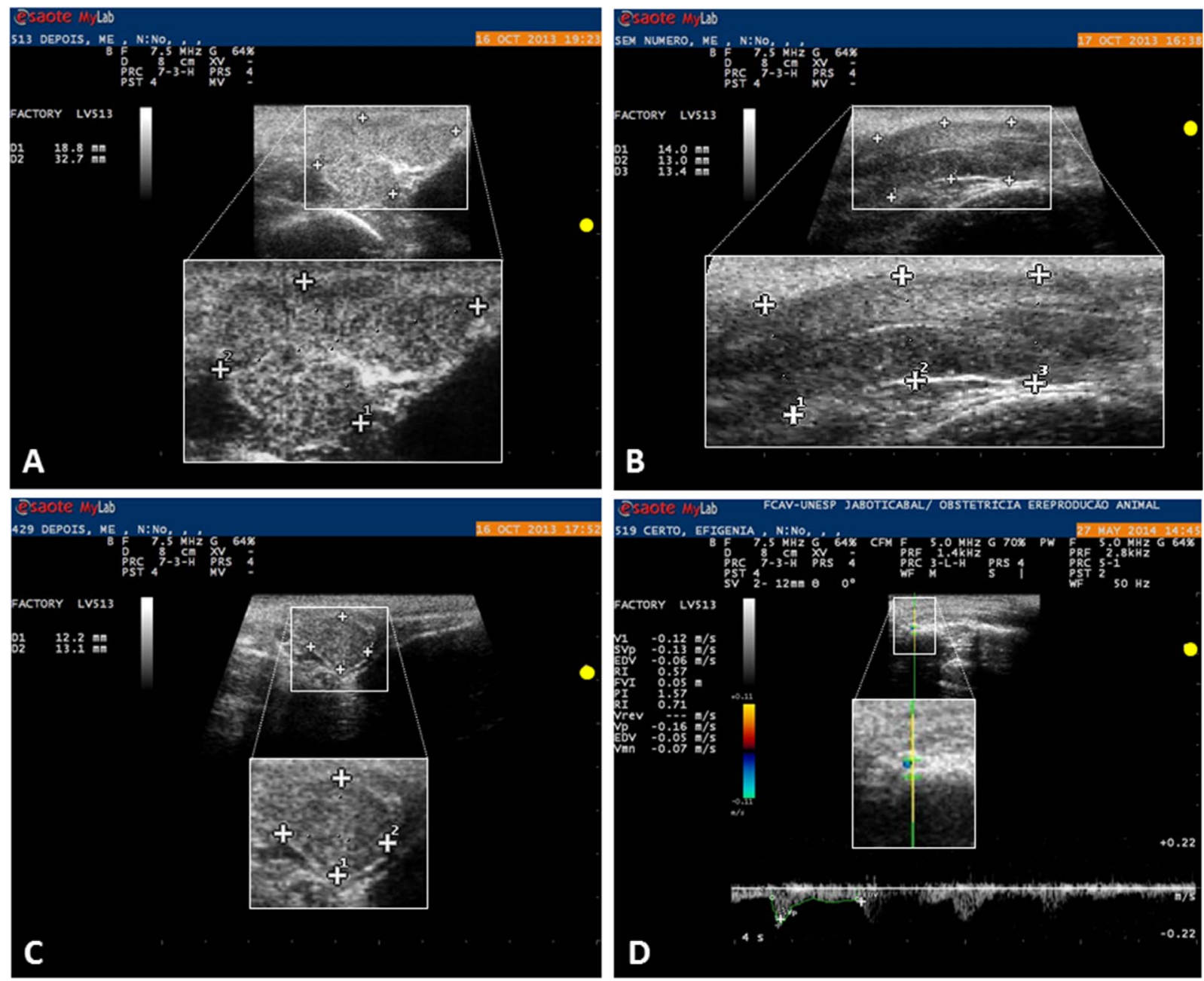

Fig 1. Photographic reproductions of ultrasonograms depicting vesicular glands (A), prostate (B) and bulbourethral gland (C) (original display size and enlargements) as well as a Doppler scan of an internal iliac artery (D) obtained in peri-(aged 8-11 months) and post-pubertal (aged 12-24 months) Dorper rams. Built-in electronic calipers (+) were used for the measurement of glandular dimensions (1-3). A green and yellow line in panel D represents a position of a caliper placed in a central area of the blood vessel (light blue) with the apertures to determine the spectral trace of blood flow as well as the spectral curve and velocimetric indices. A yellow dot on each panel corresponds to the index of the transducer (cephalic or cranial direction at transrectal scanning). (For interpretation of the references to colour in this figure legend, the reader is referred to the web version of this article.)

Color Doppler was used immediately after the conventional (grey-scale) images of the accessory sex glands were acquired to identify the internal iliac arteries (transrectal imaging; Fig. 1D). The angle between the Doppler beam and the long axis of each vessel was $\leq 60^{\circ}$. A caliper measuring between 2 and $3 \mathrm{~mm}$ in length (equivalent to $2 / 3$ of the blood vessel's diameter) was positioned in a central area of the vessel with the apertures to determine the spectral trace of blood flow as well as the spectral curve and vascular index, which were obtained automatically following software processing of the signal from the ultrasound scanner for each waveform; a minimum of three consecuitive waves were analyzed. The vascular indices studied with spectral Doppler were: peak systolic velocity $(\mathrm{PSV}, \mathrm{cm} / \mathrm{s})$; end-diastolic velocity $(\mathrm{EDV}, \mathrm{cm} / \mathrm{s})$; resistive index $(\mathrm{RI}=[\mathrm{PSV}-\mathrm{EDV}] / \mathrm{PSV})$ and pulsatility index $(\mathrm{PI}=$ [SPV-EDV]/mean velocity).

Semen was collected into an artificial vagina and the following semen characteristics were recorded immediately after collection, according to (Brazilian College of Animal Reproduction; CBRA, 1998): 1) volume (ml) measured directly in the Falcon type graduated semen collection tube; 2) sperm mass motility (scale from zero-no movement to 5-strong wave motion) determined under the microscope (LEICA CME; Bufallo, NY, USA) at $100 \times$ image magnification after a drop of semen ( $10 \mu \mathrm{l})$ was placed on the pre-heated $\left(37^{\circ} \mathrm{C}\right)$ glass slide; 3 ) sperm progressive motility (\%) evaluated after diluting $10 \mu \mathrm{l}$ of semen in $0.9 \%$ saline solution (1:400); a drop of this dilution (10-20 $\mu \mathrm{l})$ was then placed between a cover slip and a glass for microscopic examinations at $20 \times$ or $400 \times$ magnification during which the percentage of spermatozoa with progressive motility in three different fields of view was estimated; 4) spermatic vigor, or the intensity of cell movement, ranging from zero (no movement) to 5 (maximum vigor) was evaluated using the same conditions as those described for 3 ) above; 5) sperm concentration (x $10^{6}$ spermatozoa/ml) was calculated using a Neubauer chamber at $400 \times$ magnification after diluting $10 \mu$ of semen in distilled water (1:400); the final result was obtained using the 
equation: sperm concentration $=5 \times 10 \times \mathrm{N} \times 400 \times 10^{3} \mathrm{sperm} / \mathrm{ml}$, with $\mathrm{N}$ being the number of spermatozoa counted in five of the 25 squares; 6) percentage of live and dead sperm (vitality test), and 7) sperm morphology evaluated in smears stained with eosin or eosin-nigrosin (200 cells per slide visualized by immersion light microscopy at $1000 \times$ magnification). Lastly, the hypoosmotic swelling test was performed (Jeyendran et al., 1984), using $40 \mu \mathrm{l}$ of semen diluted in $2 \mathrm{ml}$ of hypoosmotic solution (consisting of equal parts of trisodium citrate and fructose at a final concentration of $125 \mathrm{mOsm} / \mathrm{l}$ ) and incubated in a water bath at $37{ }^{\circ} \mathrm{C}$ for 60 min. Subsequently, a 10- $\mu$ l sample was examined with phase contrast microscopy (LABOMED LX400 - New York Microscope Company, Hicksville, New York, USA) at $400 \times$ magnification; 100 spermatozoa per sample were counted and the percentage of spermatozoa with the visible coiling of the tail (representing an intact flagellar membrane) was recorded.

Blood samples for determination of serum testosterone concentrations were collected by jugular venipuncture into 10-ml coagulant-free vacutainers (BD Vacutainer ${ }^{\oplus}$; BD, Curitiba, Paraná, Brazil) using 21G needles (BD Vacutainer ${ }^{\circledR}$ precisionGlide $^{\mathrm{TM}}$; Curitiba, Paraná, Brazil). The samples were centrifuged at $3000 \mathrm{xg}$ for $15 \mathrm{~min}$ after $24 \mathrm{~h}$ post-collection, and harvested serum was stored at $-20{ }^{\circ} \mathrm{C}$. Testosterone measurements were accomplished by radioimmunoassay (RIA), using a commercial kit (Immunotech; Beckman Coulter, Villepinte, France), according to the manufacturer's specifications. The analytical sensitivity of the assay was $0.1 \mathrm{ng} / \mathrm{ml}$ $(0.35 \mathrm{nmol} / \mathrm{l})$ and the range of standards was $0.1-16 \mathrm{ng} / \mathrm{ml}(0.35-55.5 \mathrm{nmol} / \mathrm{l})$. All samples were analyzed in a single assay with the coefficient of variation equal to $1.95 \%$.

Statistical analyses were performed using $\mathrm{R}^{\odot}$ 3.0.3 statistical software. All data sets were tested for normality (Cramer-VonMises test) and homoscedasticity (homogeneity of variance-Box Cox analysis) prior to one-way analysis of variance (ANOVA), followed by the comparison of individual means by Tukey test. Whenever necessary (i.e., equal variance or normality tests failed), the data were transformed logarithmically $\left(\log _{\mathrm{n}}\right)$ prior to ANOVA. The chi-square test was used for the analysis of proportions and the Pearson Product Moment for correlation analyses. The significance level was set at $95 \%(P<0.05)$. All results are presented as mean \pm standard deviation (SD) of the mean unless otherwise indicated.

\section{Results and discussion}

All accessory sex glands and internal iliac arteries could be easily and repeatedly detected with trasrectal utrasonography in the rams of the present study (Fig. 1). Vesicular glands were observed near the urinary bladder, dorsolaterally, and appeared as lobulated structures with irregular contour and heterogeneous echotexture, due mainly to the presence of anechoic areas, and generally hyopechoic in comparison to the surrounding connective tissue (Fig. 1A). Their topographic location and appearance (Setchell et al., 2006; Setchell and Breed, 2006) fully matched those previously described in ruminant species. The prostate gland was seen dorsally to and spread along the pelvic urethra, from urinary bladder to the region occupied by the bulbourethral glands; slightly hypoechoic in relation to adjacent soft tissue and with homogeneous echotexture (Fig. 1B). (Suri et al., 2009), based on the histomorphological study, described the prostate gland in adult goats and sheep as a structure composed only of the disseminated part; however, those authors also reported sporadic occurrence of a structure resembling the body of the prostate, typically seen in cattle and buffaloes. The body of the prostate was not detected in any of the rams of the present study. Ovoid bulbourethral glands were located caudally to the urinary bladder, and had parenchyma exhibiting heterogeneous echotexture (Fig. 1C), which is similar to earlier findings of (Webber et al., 1988) in rams and (Santiago-Moreno et al., 2013) in the Iberian ibex.

For all variables studied, there were no differences between left and right paired glands or left and right iliac arteries $(P>0.05)$; therefore the results were averaged and anlyzed on a per animal basis. Sexually mature rams exceeded peri-pubertal animals in mean dimensions of the prostate $(P=0.03)$ and bulbourethral glands $(P=0.04$; Table 1$)$. The growth and differentiation of accessory sex glands are mainly regulated by androgens (Risbridger and Taylor, 2006), but our results indicate that more complex regulatory mechanisms must contribute to these processes. In the present study, testosterone concentrations did not vary between the peri- and post-pubertal rams, suggesting that the size and functionality of the accessory sex glands during that transition were controlled by other factors. Since body weight differed significantly between growing and sexually mature rams, it is feasible that terminal

Table 1

Summary of morphometric and echotextural characteristics (mean \pm standard deviation) of accessory sex glands in peri- (8-11 months of age) and post-pubertal (12-24 months of age) Dorper rams raised in subtropital climate. NPVs (nnumerical pixel values); pixel heterogeneity (standard deviation of numerical pixel values).

\begin{tabular}{|c|c|c|c|}
\hline Variables/Groups & Peri-pubertal $(n=24)$ & Post-pubertal $(n=21)$ & $P$ value \\
\hline \multicolumn{4}{|l|}{ Vesicular glands } \\
\hline Dimensions (mm) & $24.8 \pm 3.3$ & $24.6 \pm 3.8$ & 0.83 \\
\hline NPVs (0-255) & $181.5 \pm 20.8$ & $164.8 \pm 26.8$ & 0.02 \\
\hline Pixel heterogeneity & $29.1 \pm 2.7$ & $28.1 \pm 3.9$ & 0.34 \\
\hline \multicolumn{4}{|l|}{ Prostate } \\
\hline Dimensions & $12.9 \pm 1.2$ & $14.2 \pm 2.7$ & 0.03 \\
\hline NPVs & $99.4 \pm 36.3$ & $87.5 \pm 34.2$ & 0.18 \\
\hline Pixel heterogeneity & $32.1 \pm 8.2$ & $30.3 \pm 4.7$ & 0.36 \\
\hline \multicolumn{4}{|l|}{ Bulbourethral glands } \\
\hline Dimensions & $13.7 \pm 1.3$ & $14.7 \pm 1.8$ & 0.04 \\
\hline NPVs & $166.9 \pm 16.9$ & $141.8 \pm 29.1$ & 0.001 \\
\hline Pixel heterogeneity & $27.8 \pm 4.5$ & $28.7 \pm 4.3$ & 0.49 \\
\hline
\end{tabular}


development of male reproductive organs was governed by the somatotropic axis and/or thyroid hormones. More studies are needed in this area as they may pave the way to the development of practical methods aimed to control the onset of puberty and to enhance fertility in adult males.

Mean numerical pixel values of vesicular $(P=0.02)$ and bulbourethral glands $(P=0.001)$ were greater in peri-pubertal compared with post-pubertal Dorper rams (Table 1). This difference in pixel intensity may be due to the fact that vesicular and bulbourethral glands in pre-pubertal animals had not yet reached their full secretory ability. Vesicular glands provide most of the seminal plasma (Gradela et al., 2013; Westfalewicz et al., 2017) and fully mature glands contain more plasma-storing microcystic structures dispersed within the parenchyma of the organ, which may result in the lower echogenicity of the seminal vesicles in adult compared with prepubescent animals. Similar histophysiological changes may occur in the bulbourethral glands, which also contribute to seminal plasma volume and produce mucus-like substance discharged just prior to coitus to clean the urethra of urine (Noakes et al., 2001).

Doppler ultrasonographic examinations of the internal iliac arteries have revealed a monophasic blood flow pattern of low resistance, with long, recurrent systolic peaks, and high diastolic flow velocity. There were no significant difference between the two age groups of animals for any of the velocimetric indices recorded (PSV: $0.17 \pm 0.10 \mathrm{~cm} / \mathrm{s} ; \mathrm{EDV}$ : $0.04 \pm 0.02 \mathrm{~cm} / \mathrm{s}$; RI: $0.75 \pm 0.10$; and PI: $1.89 \pm 0.66$ ). Internal iliac arteries arise from the abdominal aorta and supply blood to accessory sex glands (Bergh and Damber, 1993). There is a paucity of studies on hemodynamic characteristics of arterial blood vessels supplying male reproductive organs in small ruminants (Zelli et al., 2013; Samir et al., 2015). In humans, the evaluation of testicular blood flow is used in general andrological assessment (Atilla et al., 1997; Pinggera et al., 2008). In veterinary practice, Doppler ultrasonography of the testicular artery is used to ascertain normal testicular function and detect certain pathological conditions (e.g., varicocele) in dogs (Zelli et al., 2013) and stallions (Pozor, 2007; Pozor and McDonnell, 2004). There are no reports in the available literature on the clinical evaluation of blood flow in internal iliac arteries. The velocimetric indices of internal iliac arteries determined in the present study in rams are similar to those described for testicular arteries in dogs (Souza et al., 2014; Zelli et al., 2013; Carrillo et al., 2012) and cats (Brito et al., 2015). A lack of significant differences in blood flow parameters between the peri- and post-pubertal animals may be interpreted to suggest that full establishment of arterial perfusion precedes the final stages of accessory gland development in growing rams. The reference ranges for velocimetric parameters of internal iliac arteries obtained in rams may be used in veterinary andrology and future studies aimed to assess the functioning of accessory sex glands.

Semen samples could only be obtained from 13 rams, namely from 8/21 (38\%) peri-pubertal rams and from 5/24 post-pubertal animals $(21 \% ; P<0.05)$. All semen samples were considered normal, according to the CBRA (1998) standards. The only semen characteristic that differed between the two subsets of rams in the present study was the percentage of sperm exhibiting tail colining after the hypoosmotic swelling test, which was greater $(P=0.04)$ in sexually mature Dorper rams (Table 2$)$. However, due mainly to the low semen collection rates in both age groups of rams, the present observations on semen characteristics should be viewed with caution. The results of the hypoosmotic swelling test correlated positively with the percent motility in the fresh ejaculates from fertile and subfertile men (Lin et al., 1998), but in the present study there was no relationship between the percentage of coiling and sperm mass motility $(r=0.15 ; P=0.63)$, progressive motility $(r=0.20 ; P=0.51)$ or spermatic vigor $(r=0.31 ; P=0.30)$.

Spermatic vigor $(r=-0.69, P=0.009)$ and progressive motility $(r=-0.61, P=0.03)$ were both correlated with serum testosterone concentreations. The volume of ejaculate was directly related to PSV $(r=0.79, \mathrm{P}=0.001)$ and EDV $(r=0.67, P=0.01)$ of the intrenal iliac arteries in rams (Table 3). There were no significant correlations among semen characteristics and dimensions or echotextural attributes of accessory sex glands. Ultrasonographic attributes of the accessory sex glands in rams are, therefore, poor indicators of morphological semen characteristics determined in fresh ejaculates. It would be of interest to examine if echotextural values for the accessory sex glands, which may be indicative of chemical composition their secretions (Ahmadi et al., 2013), were related to sperm survival time and cryotolerance that are influenced, at least to some extent, by seminal plasma constituents.

In summary, transrectal B-mode and spectral Doppler ultrasonography enabled the evaluation of accessory sex glands and blood flow indices of the internal iliac arteries supplying the glandular organs in rams. The attainment of puberty was associated with the changes in size and echogenicity of accessory sex glands, and so these variables can be accurate markers of pubertal onset in rams. The percentage of sperm cells with an intact flagellar membrane after the hypoosmotic test was a single characteristic that varied significantly between the peri- and post-pubertal rams. Serum testosterone concentrations and Doppler blood flow indices of the

Table 2

Semen characteristics and serum testosterone concentrations (mean \pm standard deviation) in peri- (8-11 months of age) and post-pubertal (12-24 months of age) Dorper rams raised in subtropital climate.

\begin{tabular}{|c|c|c|c|}
\hline Variables/Groups & Peri-pubertal $(n=5)$ & Post-pubertal $(n=8)$ & $P$ value \\
\hline Volume (ml) & $1.0 \pm 0.3$ & $1.1 \pm 0.4$ & 0.43 \\
\hline Mass motility (0-5) & $3.6 \pm 1.1$ & $3.9 \pm 0.8$ & 0.62 \\
\hline Progressive motility (\%) & $75.0 \pm 26.9$ & $55.9 \pm 39.3$ & 0.43 \\
\hline Spermatic vigor (0-5) & $3.6 \pm 1.1$ & $4.0 \pm 0.5$ & 0.14 \\
\hline Sperm concentration $\left(\times 10^{6} / \mathrm{ml}\right)$ & $4.0 \pm 0.9$ & $5.9 \pm 2.5$ & 0.60 \\
\hline Total defects (\%) & $12.4 \pm 16.7$ & $8.4 \pm 5.0$ & 0.53 \\
\hline Vitality (\%) & $97.8 \pm 1.3$ & $90.2 \pm 15.4$ & 0.30 \\
\hline Tail coiling (\%) & $38.4 \pm 3.5$ & $51.6 \pm 11.9$ & 0.04 \\
\hline Testosterone (ng/ml) & $6.7 \pm 6.7$ & $6.4 \pm 5.8$ & 0.90 \\
\hline
\end{tabular}


Table 3

Significant correlations between serum testosterone concentrations or blood flow indices in the internal iliac arteries (input variables), and semen characteristics (output variables) determined in thirteen Dorper rams aged 8-24 months. PDV: peak systolic velocity; and EDV: end-diastolic velocity.

\begin{tabular}{lll}
\hline Input variable $(\mathrm{x})$ & Output variables $(\mathrm{y})$ & Regression equations \\
\hline Testosterone $(\mathrm{ng} / \mathrm{ml})$ & Spermatic vigor $(0-5)$ & $\mathrm{y}=-0.08 \mathrm{x}+4.59$ \\
& Progressive motility (\%) & $\mathrm{y}=-1.5 \mathrm{x}+94.2$ \\
PSV $(\mathrm{cm} / \mathrm{s})$ & Volume $(\mathrm{ml})$ & $\mathrm{y}=1.45 \mathrm{x}+0.75$ \\
EDV $(\mathrm{cm} / \mathrm{s})$ & Volume $(\mathrm{ml})$ & $\mathrm{y}=7.52 \mathrm{x}+0.80$ \\
\end{tabular}

ram's internal iliac arteries were correlated with semen progressive motility, vigor and the amount of ejaculate. The present results indicate that both ultrasound techniques have the makings of non-invasive methods for monitoring the development and proper functioning of the accessory sex organs, and may aid in the assessment of sexual development and breeding soundness evaluation in small ruminants.

\title{
Conflict of interest
}

\author{
None to declare.
}

\section{Acknowledgements}

Thanks are extended to the "Cabanha Malu Dorper Farm" (São Roque, SP, Brazil) for the provision and housing of experimental animals. MEFO and WRRV are fellows of the CNPq.

\section{References}

Ahmadi, B., Mirshahi, A., Giffin, J., Oliveira, M.E.F., Gao, L., Hahnel, A., Bartlewski, P.M., 2013. Preliminary assessment of the quantitative relationships between testicular tissue composition and ultrasonographic image attributes in the ram. Vet. J. 198, 282-285.

Alves, J.M., McManus, C., Lucci, C.M., Carneiro, H.C.R., Dallago, B.S., Cadavid, V.G., Marsiaj, P.A.P., Louvandini, H., 2006. Estação De Nascimento E Puberdade Em Cordeiros Santa Inês, vol. 35. Revista Brasileira Zootecniapp. 958-966.

Atilla, M.K., Sargin, H., Yilmaz, Y., Odabas, O., Keskin, A., Aydin, S., 1997. Undescended testes in adults: clinical significance of resistive index values of the testicular artery measured by Doppler ultrasound as a predictor of testicular histology. J. Urol. 158, 841-843.

Bergh, A., Damber, J.E., 1993. Vascular controls in testicular physiology. In: de Kretser, D.M. (Ed.), Molecular Biology of the Male Reproductive System. Academic Press, New York, pp. 439-468.

Brito,M, B.S., Feliciano, M.A.R., Coutinho, L.N., Uscategui, R.R., Simões, A.P., Maronezi, M.C., Almeida, V.T., Crivelaro, R.M., Gasser, B., Pavan, L., Russiano, W.R.R., 2015. Doppler and contrast-enhanced ultrasonography of testicles in adult domestic felines. Reprod. Dom. Anim. 50, $730-734$.

CBRA, 1998. Colégio brasileiro de reprodução animal. Manual Para Exame Andrológico E Avaliação De sêmen Animal, 2 nd ed. Belo Horizontepp. 49.

Carillo, J.D., Soler, M., Lucasm, X., Agut, A., 2012. Colour and pulsed Doppler ultrasonographic study of the canine testis. Reprod. Dom. Anim. 47, 655-659.

Carvalho, C.F., Chammas, M.C., Giovanni, G.C., 2008. Physical principles of Doppler ultrasonography. Ciênc. Rural $38,872-879$.

Chandolia, R.K., Bartlewski, P.M., Omeke, B.C., Beard, A.P., Rawlings, N.C., Pierson, R.A., 1997. Ultrasonography of the developing reproductive tract in ram lambs: effects of a GnRH agonist. Theriogenology 48, 99-117.

Clark, S.G., Althouse, G.C., 2003. B-mode ultrasonographic examination of the accessory sex glands of boars. Theriogenology 57, $2003-2013$.

Gouletsou, P.G., Fthenakis, G.C., 2010. Clinical evaluation of reproductive ability of rams. Small Rumin. Res. 92, 45-51.

Gradela, A., Nunes, A.K.R., Matos, M.H.T., Franzo, V.S., Faria, M.D., Moreira,M, B., Santos, J.M., 2013. Descrição morfológica e morfométrica da glândula vesicular de cobaias durante o desenvolvimento pós-natal. Pesq. Vet. Bras. 33, 942-948.

Gumbsch, P., Holzmann, A., Gabler, C., 2002. Colour-coded duplex sonography of the testes os dogs. Vet. Rec. 151, $140-144$.

Jeyendran, R.S., Ven Van Der, H.H., Perez-Pelaez, M., Crabo, B.G., Zaneveld, L.J.D., 1984. Development of an assay to assess the functional integrity of the human sperm membrane and its relationship to other semen characteristics. J. Reprod. Fertil. 70, 210-228.

Lin, M.H., Morshedi, M., Srisombut, C., Nassar, A., Oehninger, S., 1998. Plasma membrane integrity of cryopreserved human sperm: an investigation of the results of the hypoosmotic swelling test, the water test, and eosin-Y staining. Fertil. Steril. 70, 1148-1155.

Mann, T., 1946. Studies on the metabolism of semen: fructose as a normal constituent of seminal plasma. Biomchem. J. 40, $4481-4491$.

Muramoto, C., Starnan, F.A., Hagen, S.C.F., Pinto, A.C.B.C., Oliveira, C.M., Faustino, M., Talib, M.F., Torres, L.N., 2011. Avaliação ultrassonografica de linfonodos na pesquisa de metástases em neoplasia mamaria em cadelas. Pesq. Vet. Bras. 31, 1006-1013.

Noakes, D.E., Parkinson, T.J., England, G.C.W., 2001. Normal reproduction in male animals. Arthur's Veterinary Reproduction and Obstetrics, eighth edition. pp. $673-694$.

Omer, R., Giffin, J., Hahnel, A., Bartlewski, P.M., 2012. Relationships of ultrasonographic and magnetic resonance image attributes to the histomorphology of ram testes. Reprod. Biol. 12, 355-361.

Pang, S.F., Chow, P.H., Wong, T.M., 1979. The role of the seminal vesicles, coagulating glands and prostate glands on the fertility and fecundity of mice. J. Reprod. Fertil. 56, 129-132.

Pinggera, G.M., Mitterberger, M., Bartsch, G., Strasser, H., Gradl, J., Aigner, F., Pallwein, L., Frauscher, F., 2008. Assessment of the intratesticular resistive index by colour Doppler ultrasonography measurements as a predictor of spermatogenesis. BJU Int. 101, 722-726.

Pozor, M.A., McDonnell, S.M., 2004. Color Doppler ultrasound evaluation of testicular blood flow in stallions. Theriogenology 61, 799-810.

Pozor, M.A., 2007. Evaluation of testicular vasculature in stallions. Clin. Tech. Equine Pract. 6, 271-277.

Risbridger, G.P., Taylor, R.A., 2006. Physiology of the male accessory sex structures: the prostate gland, seminal vesicles, and bulbourethral glands. Knobil and Neill's Physiology of Reproduction, third edition. Elsevierpp. 1149-1172.

Samir, H., Sasaki, K., Ahmed, E., Karen, A., Nagaoka, K., El Sayed, M., Taya, K., Watanabe, G., 2015. Effect of a single injection of gonadotropin-releasing hormone $(\mathrm{GnRH})$ and human chorionic gonadotropin (hCG) on testicular blood flow measured by color Doppler ultrasonography in male Shiba goats. J. Vet. Med. Sci. 77, $549-556$.

Santiago-Moreno, J., Toledano-Díaz, A., Castaño, C., Coloma, M.A., Esteso, M.C., Prieto, M.T., Delgadillo, J.A., López-Sebastián, A., 2013. Photoperiod and melatonin treatments for controlling sperm parameters, testicular and accessory sex glands size in male Iberian ibex: a model for captive mountain ruminants. Anim. Reprod. 
Sci. 139, 45-52.

Setchell, B.P., Breed, W.G., 2006. Anatomy, Vasculature, and innervation of the male reproductive tract. Knobil and Neill's Physiology of Reproduction, third edition. Elsevierpp. 771-825.

Snowder, G.D., Stellflug, J.N., Van Vleck, L.D., 2002. Heritability and repeatability of sexual performance scores of rams. J. Anim. Sci. 80, 1508-1511.

Souza, M.B., Barbosa, C.C., Pereira, B.S., Monteiro, C.L.B., Pinto, J.N., Linhares, J.C.S., Silva, L.D.M., 2014. Doppler velocimetric parameters of the testicular artery in healthy dogs. Res. Vet. Sci. 96, 533-536.

Suri, S., Sudhakar, L.S., Bhardwaj, R.L., 2009. Anatomical studies of the prostate gland of Gaddi goat and sheep. J. Anim. Sci. 79, $294-296$.

Webber, J.A., Hilt, C.J., Woods, G.L., 1988. Ultrasonographic appearance of bull accessory sex glands. Theriogenology 29, $1347-1355$.

Westfalewicz, B., Dietrich, M.A., Mostek, A., Partyka, A., Bielas, W., Niżański, W., Ciereszko, A., 2017. Analysis of bull (Bos taurus) seminal vesicle fluid proteome in relation to seminal plasma proteome. J. Dairy Sci. 100, 2282-2298.

Zelli, R., Troisi, A., Elad Ngonput, A., Cardinali, L., Polisca, A., 2013. Evaluation of testicular artery blood flow by Doppler ultrasonography as a predictor of spermatogenesis in the dog. Res. Vet. Sci. 95, 632-637. 